Gut, 1982, 23, 734-738

\title{
Antipyrine elimination as a dynamic test of hepatic functional integrity in obstructive jaundice
}

\author{
G A D McPHERSON, * I S BENJAMIN, A R BOOBIS, M J BRODIE, $\dagger$
}

C HAMPDEN, and L H BLUMGART

From the Departments of Surgery and Clinical Pharmacology, Royal Postgraduate Medical School,
Hammersmith Hospital, London

SUMmaRY Antipyrine elimination was studied in 29 patients with obstructive jaundice. Antipyrine half-lives calculated using plasma concentrations at four and 24 hours ('short antipyrine test') were significantly correlated with those calculated using six time points $(\mathrm{p}<0.001)$. Mean antipyrine half-life was $28 \cdot 3 \pm 8$ hours (standard error) and was significantly longer than in normal subjects $(\mathrm{p}<0 \cdot 001)$. Antipyrine half-life did not correlate with standard biochemical liver function tests, but correlated positively with the postoperative half-time for clearance of endogenous bilirubin $(\mathrm{p}<0.05)$, and negatively with hepatic cytochrome $\mathrm{P}-450$ content measured in peroperative liver biopsies $(\mathrm{p}<0.05)$. Of six patients with antipyrine half-life $>20$ hours, four died, one preoperatively of gastrointestinal haemorrhage and three postoperatively of sepsis. Serial short antipyrine tests were performed in 13 patients before and after biliary drainage. Those with an initial antipyrine half-life greater than 15 hours showed significant changes after drainage, while those with an antipyrine half-life less than 15 hours did not. The test of antipyrine half-life may aid in selecting high risk patients with obstructive jaundice for percutaneous biliary drainage before definitive surgery, and in determining the optimal time for such preliminary biliary decompression.

Surgery for obstructive jaundice carries a high mortality rate, ${ }^{1}$ which may be as great as $25-30 \%$ in pancreatic cancer. ${ }^{2}$ Several risk factors, such as infection, impaired renal function, low plasma albumin and increasing age have been identified, and the overall mortality is related to the depth of jaundice. This has created interest in the concept of a two-stage approach, with preliminary percutaneous transhepatic biliary decompression to relieve jaundice and impaired hepatic function before definitive surgery. As this procedure itself carries hazards, ${ }^{3}$ selection of patients at highest risk from surgery would be valuable. Static tests such as serum bilirubin and hepatic enzymes are unhelpful and dynamic studies using bromsulphthalein and indocyanine green are unreliable in the presence of hyperbilirubinaemia.

\footnotetext{
- Address for correspondence: G A D McPherson, FRCS, Department of Surgery, Royal Postgraduate Medical School, Hammersmith Hospital, Du Cane Road, London W12 0HS.

+ Present address: Department of Medicine, Western Infirmary, Glasgow.

Received for publication 7 January 1982
}

Antipyrine is a minor analgesic which depends almost entirely on oxidation in the liver for elimination, making it a particularly suitable probe for studies of drug metabolism. ${ }^{4}$ In this study, the hepatic elimination of antipyrine has been measured preoperatively in patients with biliary obstruction before and during percutaneous drainage, and assessed as a dynamic test of hepatic metabolic performance. Comparison has been made with operative outcome, static tests of liver function such as bilirubin, albumin, and liver enzymes, as well as the time taken for the jaundice to clear after biliary decompression (bilirubin half-life) and in vitro oxidation assessed from cytochrome P-450 content. Normally, clearance studies with antipyrine take 48 hours and require six blood samples. We have examined the possibility of relying on two samples, taken over 24 hours, thereby making the clearance study more suitable for routine clinical use. The 24 hour test was designated the 'short antipyrine test'. Serial short tests were completed on 13 jaundiced patients undergoing biliary decompression. 
Methods

\section{PATIENTS}

Sixteen patients

Sixteen patients with extrahepatic jaundice diagnosed by percutaneous cholangiography were investigated. There were 11 males and five females, ranging from 41-71 years of age (mean 58 years). Fifteen had malignant obstruction (12 carcinoma of bile duct, three carcinoma of head of pancreas) and one had benign obstruction with secondary biliary cirrhosis after previous surgery for cholelithiasis. After an oral dose of $600 \mathrm{mg}$ antipyrine 72 hours before surgery, blood samples were obtained at two, four, eight, 12, 24, and 48 hours for analysis of antipyrine and the plasma was stored at $-20^{\circ} \mathrm{C}$ until analysis. Standard biochemical liver function tests were obtained 24 hours before surgery. In 13 patients a liver biopsy was taken during surgery for histology, and tissue which was surplus to histological requirement was used for determination of microsomal cytochrome P-450 content. After biliary decompression by insertion of a percutaneous transhepatic drainage catheter, by surgical insertion of a T-tube above the obstruction or by surgical biliaryenteric bypass, the fall of serum bilirubin was followed and the half-life of its disappearance calculated by least squares regression analysis.

\section{Thirteen patients}

After the initial study was completed a further 13 patients had serial antipyrine half-life measured before and during biliary drainage, using the 24hour short antipyrine test. Eight of these patients were treated by preliminary percutaneous transhepatic drainage, while five had a surgical biliaryenteric bypass. In this group there were nine males and four females ranging from 40-76 years of age (mean 52 years). Ten had malignant obstruction (eight proximal bile duct cancer, two carcinoma of head of pancreas) and three had benign obstruction (two had common duct stones, one had sclerosing cholangitis). After an oral dose of $600 \mathrm{mg}$ antipyrine 72 hours before biliary decompression, samples were obtained at four and 24 hours for analysis of antipyrine and the plasma stored at $-20^{\circ} \mathrm{C}$ until analysis. After decompression the test was repeated weekly, together with standard biochemical liver function tests.

\section{Controls}

Antipyrine clearance values measured using an identical protocol in healthy volunteers on a normal diet were available from a previous study. ${ }^{5}$
ANALYSIS

Antipyrine was measured by gas chromatography. ${ }^{6}$ Half-lives $\left(t_{0.5}\right)$ were calculated by least squares regression analysis; apparent volumes of distribution (V) by back extrapolation of the terminal phase of the concentration-time curve; and clearances $(\mathrm{Cl})$ from the expression

$$
\mathrm{Cl}=\left(0 \cdot 693 / \mathrm{t}_{0.5}\right) \times \mathrm{V} \text {. }
$$

Serum bilirubin and albumin concentrations and aspartate transaminase and alkaline phosphatase activities were measured using a Technicon Plus autoanalyser.

The liver biopsy material was placed in ice cold $0.25 \mathrm{M}$ phosphate buffer ( $\mathrm{pH} 7.25$, containing $0.15 \mathrm{M}$ potassium chloride and $1 \mathrm{mM}$ EDTA) immediately upon removal from the patient. Microsomal fractions were isolated and stored at $-80^{\circ} \mathrm{C}$ in aliquots with a protein concentration of $8-16 \mathrm{mg} / \mathrm{ml}$ until analysis of cytochrome P-450 (P-450) content could be performed as previously described. ${ }^{7}$

Statistics were performed by Student's $t$ test for unpaired values. First order correlation coefficients between each pair of parameters were obtained by least squares linear regression analysis.

\section{Results}

Mean antipyrine half-life $\left(\mathrm{APt}_{0.5}\right)$ in the initial group of 16 patients was $28 \cdot 3 \pm 8$ hours (SEM) and the mean antipyrine clearance $0.35 \pm 0.04 \mathrm{ml} / \mathrm{min} / \mathrm{kg}$. Despite the wide range of antipyrine half-lives (10.5-142 hours) these values and those for clearance were significantly different $(p<0.001)$ from the corresponding values for the control population previously studied $\left(\mathrm{APt}_{0.5} \quad 10.4 \pm 0.4\right.$ hours, clearance $0.70 \pm 0.03 \mathrm{ml} / \mathrm{min} / \mathrm{kg}$ ). Six patients had values for $\mathrm{APt}_{\mathbf{0} .5}$ greater than 20 hours, and four of these died (Fig. 1), one of variceal bleeding before surgery could be undertaken and the other three from sepsis after major resectional surgery. This mortality differed significantly from that found in patients with $\mathrm{APt}_{0.5}$ less than 20 hours (0/10, $\mathrm{p}<0.05$, Fisher's exact test).

Mean values of preoperative standard biochemical liver function tests, peroperative hepatic cytochrome $\mathrm{P}-450$ content, and postoperative halflives of endogenous bilirubin $\left(\mathrm{BILt}_{0.5}\right)$ are shown in Table 1. Hepatic cytochrome P-450 content in the livers of these patients with severe obstructive jaundice was comparable with that found in patients with hepatitis and cirrhosis, and was only one-third of that of the normal liver. ${ }^{8}$ First-order correlation coefficients for $\mathrm{APt}_{0.5}, \mathrm{P}-450, \mathrm{BILt}_{0.5}$ and liver function tests in 13 patients for whom all parameters 
Table 1 Mean ( $\pm S E M)$ preoperative biochemical liver function tests, peroperative hepatic cytochrome $P-450$ content $(P-450)$, and postoperative endogenous serum bilirubin half-life (Bil to.s) in patients with obstructive jaundice

\begin{tabular}{|c|c|c|c|}
\hline Parameter & $n$ & Mean $\pm S E M$ & Normal values \\
\hline $\begin{array}{l}\text { Bilirubin } \\
\text { AST } \\
\text { ALKPHOS } \\
\text { Albumin } \\
\text { P-450 }\end{array}$ & $\begin{array}{l}16 \\
16 \\
16 \\
16 \\
13\end{array}$ & $\begin{array}{l}295 \pm 31 \mu \mathrm{mol} / \\
124 \pm 22 \mathrm{IU} / \\
698 \pm 96 \mathrm{IU} / \\
34 \pm 1 \mathrm{~g} / 1 \\
0 \cdot 16 \pm 0.02 \mathrm{nmol} / \mathrm{mg} \\
\quad \text { protein }\end{array}$ & 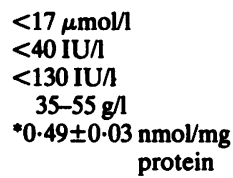 \\
\hline BIL CL & 14 & $11 \pm 5 \cdot 8$ days & - $\quad p-0.0$ \\
\hline
\end{tabular}

- Taken from Brodie, Boobis, Bulpitt, and Davies (1981). ${ }^{8}$

AST=aspartate transaminase. ALKPHOS=alkaline phosphatase.

were available are listed in Table $2 . \mathrm{APt}_{0.5}$ correlated positively with BILt $_{0.5}$ (Fig. 2) and negatively with $\mathrm{P}-450$ at the $5 \%$ level of significance. There were no significant correlations with preoperative standard liver function tests. P-450

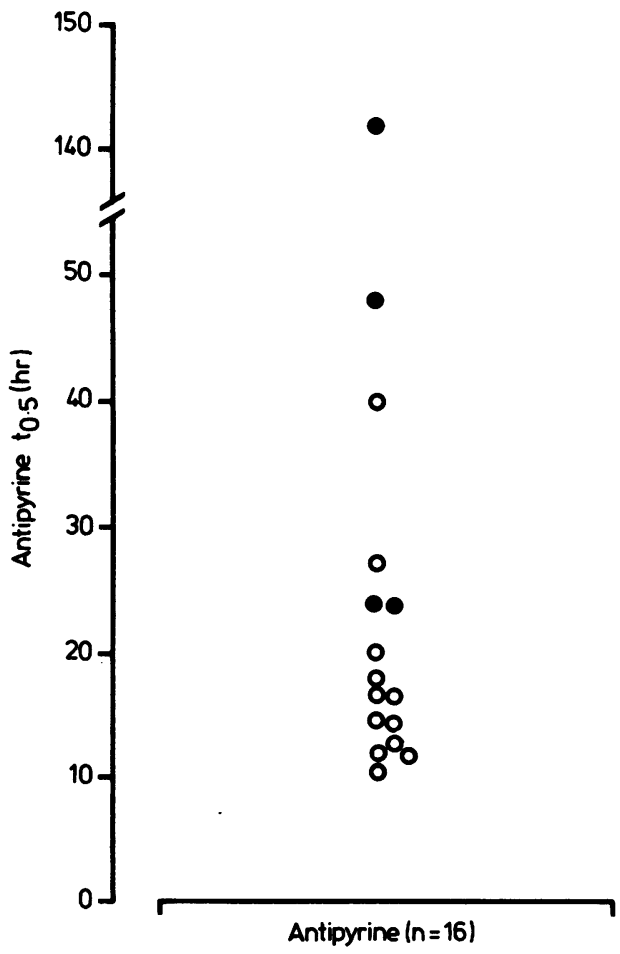

Fig. 1 Antipyrine half-lives in patients with obstructive jaundice before surgical decompression.

○ Survived. • Died.
Table 2 Correlation matrix for antipyrine half-life (AP $t_{0.5)}$ with hepatic cytochrome P-450 (P-450) content, endogenous serum bilirubin half-life $\left(B I L t_{0.5}\right)$ after drainage and results of preoperative biochemical liver function tests in 13 patients with obstructive jaundice

\begin{tabular}{lrrrrrr}
\hline & $\begin{array}{l}\text { AP } \\
t_{0.5}\end{array}$ & $P-450$ & \multicolumn{1}{c}{$\begin{array}{l}\boldsymbol{t}_{0.5} \\
\text { (1L }\end{array}$} & $\begin{array}{l}\text { Albu- } \\
\text { min }\end{array}$ & AST & $\begin{array}{l}\text { Bili- } \\
\text { rubin }\end{array}$ \\
\hline P-450 & $-0.55^{*}$ & & & & & \\
BIL t 0.5 & $0.60^{*}$ & -0.24 & & & & \\
Albumin & -0.46 & 0.09 & -0.32 & & & \\
AST & 0.12 & $-0.60^{*}$ & 0.24 & 0.10 & & \\
Bilirubin & -0.05 & $-0.60^{*}$ & 0.06 & -0.22 & 0.28 & \\
ALKPHOS & -0.28 & 0.32 & -0.28 & -0.04 & 0.08 & 0.07 \\
\hline
\end{tabular}

Values shown are first order correlation coefficients between each pair of variables in the Table.

* $\mathrm{p}<0.05$.

AST $=$ aspartate transaminase. ALKPHOS=alkaline phosphatase.

showed significant negative correlations with both AST and bilirubin levels. In addition, there was no correlation of $\mathrm{APt}_{0.5}$ with duration of illness and percentage weight loss.

$\mathrm{APt}_{0.5}$ was recalculated using the plasma concentrations at four and 24 hours only. There was a highly significant correlation between these values and the half-life values obtained using all six plasma samples $(r=0.995, p<0.001)$ (Fig. 3). Thus, although the short two sample test can be regarded as only semi-quantitative, it provides a reliable measure of the $\mathrm{APt}_{0.5}$.

Serial short antipyrine tests in 13 patients with intrahepatic obstructive jaundice showed that the $\mathrm{APt}_{0.5}$ did not change in the five patients in whom the initial value was less than 15 hours. There were

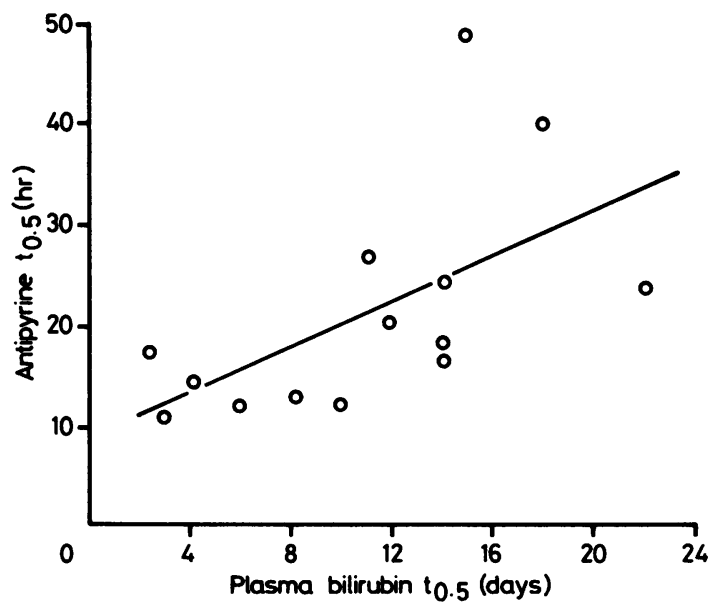

Fig. 2 Correlation between preoperative antipyrine and postoperative endogenous bilirubin half-lives in patients with obstructive jaundice. $r=0.60(p<0.05)$. 


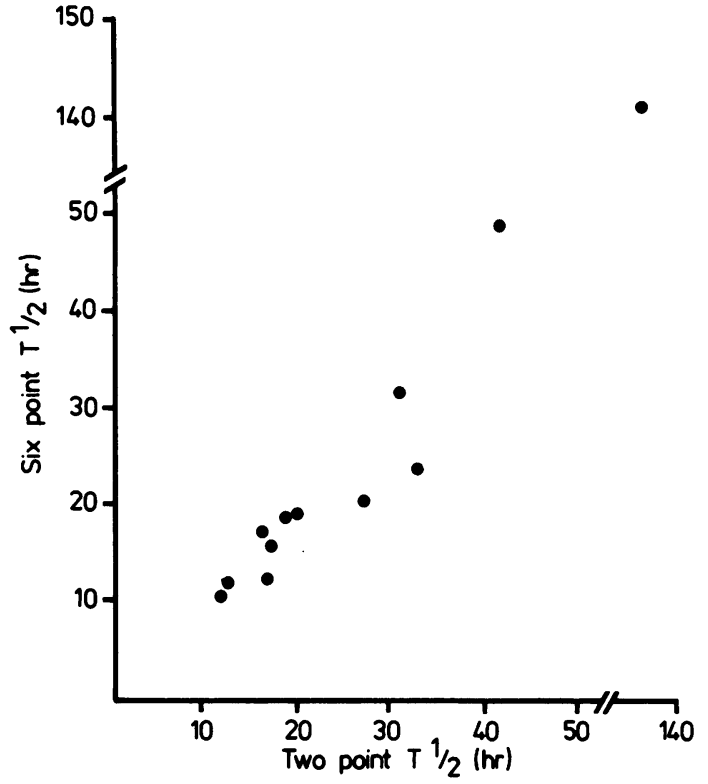

Fig. 3 Correlation between preoperative antipyrine $t_{0.5}$ using six points over 48 hours and the antipyrine $t_{0.5}$ recalculated using antipyrine levels at four and 24 hours. $r=0.967(p<0.001)$.

no postoperative complications in these patients and all cleared their jaundice with a mean $\mathrm{t}_{0.5}$ for serum bilirubin of 8.5 days (range 3.8-13 days). In the eight patients in whom the initial $\mathbf{A P t}_{0.5}$ was greater than 15 hours (Fig. 4) only four improved during drainage and two showed a marked increase in $\mathrm{APt}_{0.5}$ to greater than 40 hours, one of whom subsequently died after surgery. Two of these eight patients failed to clear their serum bilirubin after drainage.

\section{Discussion}

While patients with intrinsic hepatocellular disease show impaired hepatocellular metabolic capacity, ${ }^{8}$ the situation is less clear in patients with extrahepatic obstructive jaundice. ${ }^{10}$ The antipyrine half-life in the present series of patients showed a wide range from normal values to as high as 142 hours, and these values showed no correlation with the results of standard 'static' liver function tests. However, antipyrine half-life did show a significant correlation with the $\mathrm{BILt}_{0.5}$ after biliary drainage. Moreover, there was a significant correlation with the in vitro cytochrome P-450 content of liver biopsy material. Therefore the $\mathrm{APt}_{0.5}$ preoperatively appears to provide a good index of in vivo oxidation

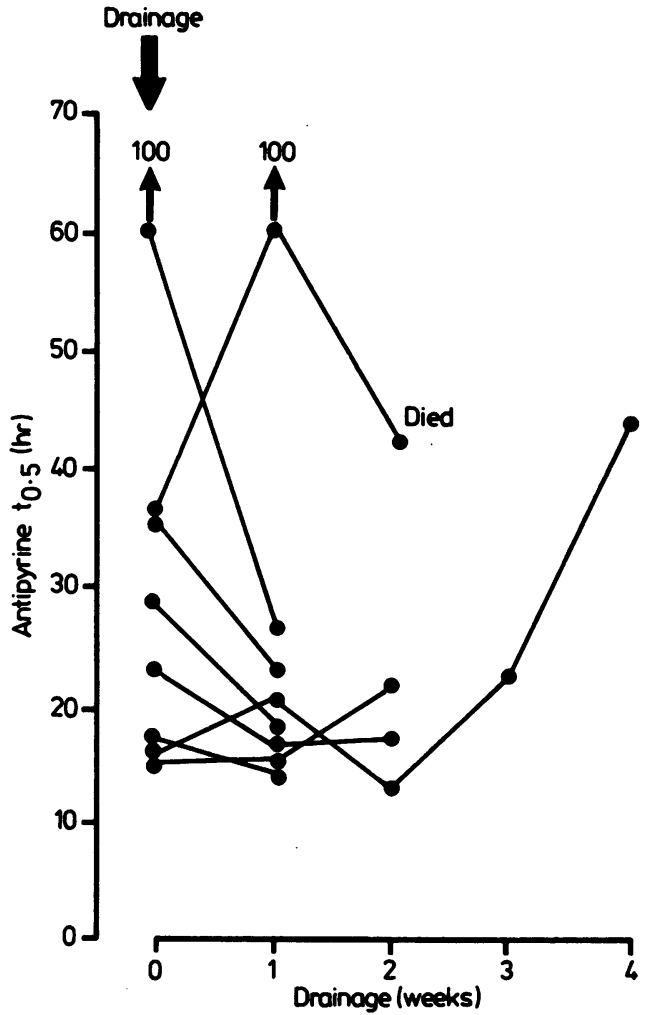

Fig. 4 Serial short antipyrine tests on eight patients whose initial $t_{0.5}$ was greater than 15 hours.

in patients with obstructive jaundice, whereas the serum bilirubin concentration and liver enzymes did not show such correlations. It may thus be more rational to base the assessment of risk from impaired hepatic function on a dynamic test such as this one, than on standard tests of liver function. It is interesting to note that the four deaths in this series have occurred in patients with grossly raised halflives ( $>20$ hours), although of course it is not possible to state from this small group whether the test may have a predictive value for the risk of surgery.

Hepatic metabolic capacity may be affected by other factors in addition to obstructive jaundice, including impaired nutrition associated with malignancy. While this may be supported by the grossly raised levels of $\mathrm{APt}_{\mathbf{0 . 5}}$ in three patients with unresectable tumours, there was no correlation with duration of illness, percentage weight loss, or other nutritional parameters, including serum albumin. The 'short' two sample test over 24 hours showed a highly significant correlation with the full six-sample 
48 hour test $(\mathrm{p}<0.001)$. This modification may thus allow a measure of the functional integrity of the liver in obstructive jaundice that is rapid and clinically applicable. As most dynamic tests of metabolism based on drug elimination are timeconsuming or technically complex, the short antipyrine test may provide a valuable addition to our investigations that is acceptably simple in a clinical situation.

Patients with obstructive jaundice have a high surgical mortality, and, although a variety of adverse prognostic factors have been determined, it is not easy to identify precisely those patients at greatest risk. Percutaneous tubal decompression of the obstructed biliary tract has been widely advocated as a preoperative measure to reduce the surgical risk. Percutaneous drainage is, however, a technique that in itself carries major hazards, and it may be advisable to restrict its use to that group of patients whose liver function is most impaired. In 13 patients who were studied serially before and after biliary drainage, we found that antipyrine half-lives less than 15 hours did not change significantly, and in these patients the plasma bilirubin cleared normally. Those eight patients in whom the $\mathrm{APt}_{0.5}$ was initially greater than 15 hours, however, followed two distinct patterns. Five showed improvement in $\mathrm{APt}_{0.5}$ and normal clearance of bilirubin. Three showed deterioration, with two failing to clear bilirubin at all, and a third showing a rise in bilirubin after a technically successful decompression. All three of these patients had unresectable tumours and one died six days after surgery. Thus high antipyrine half-life may indicate serious hepatocellular failure that may not respond rapidly to relief of biliary obstruction.

There are at present no reliable criteria to guide the clinician in determining the correct duration of biliary drinage, and deciding when the patient is fit for major surgery. The serum bilirubin is, at best, a crude yardstick, and a dynamic measure of hepatic function may be of greater value in this situation. In those patients in the study who showed rapid improvement of $\mathrm{APt}_{0.5}$ after drainage, the test may possibly have provided an indication of readiness for operation. Some, however, failed to improve during drainage. Whether this group represents patients in whom surgery is as well undertaken early as after a delay, or in whom surgery should be avoided entirely and non-operative methods used, has yet to be determined. The use of a metabolic probe such as the short antipyrine test may help to elucidate some of these problems, and may usefully be included as part of a protocol for investigation of the value of preliminary percutaneous drainage in the setting of a controlled trial.

G A D McPherson is a Wellcome Research Fellow and I S Benjamin is in receipt of a Cancer Research Campaign grant. We wish to thank Brigitte Studley for preparing the manuscript.

\section{References}

1 Nakase A, Matsumoto Y, Uchida K, Honjo I. Surgical treatment of cancer of the pancreas and periampullary region. Ann Surg 1977; 185: 52-7.

2 Benjamin IS. Tumour and host. Aims and decisions in pancreatic cancer. In: Cohn I, Hastings PR, eds. Pancreatic cancer. Geneva: UICC, 1981: 103-13.

3 McPherson GAD, Benjamin IS, Nathanson B, Blenkharn IB, Bowley NB, Blumgart LH. The advantages and disadvantages of percutaneous transhepatic biliary drainage (PCD) as part of a staged approach to obstructive jaundice. Gut 1981; 22: A427.

4 Vessell ES. The antipyrine test in clinical pharmacology: conceptions and misconceptions. Clin Pharmacol Ther 1979; 26: 275-306.

5 Boobis AR, Brodie MJ, Kahn GC, Fletcher DR, Saunders JH, Davies DS. Monooxygenase activity of human liver in microsomal fractions of needle biopsy specimens. Br J Clin Pharmacol 1980; 9: 11-19.

6 Lindgren S, Collste P, Norlander B, Sjoqvist F. Gas chromatographic assessment of the reproducibility of phenazone plasma half-life in young healthy volunteers. Eur J Clin Pharmacol 1974; 7: 381-5.

7 Brodie MJ, Boobis AR, Toverud E-L et al. Drug metabolism in white vegetarians. Br J Clin Pharmacol 1980; 9: 523-5.

8 Brodie MJ, Boobis AR, Bulpitt CJ, Davies DS. Influence of liver disease and environmental factors on hepatic monooxygenase activity in vitro. Eur $J$ Clin Pharmacol 1981; 20: 39-46.

9 Branch RA, Herbert CM, Read AE. Determinants of serum antipyrine half-lives in patients with liver disease. Gut 1973; 14: 569-73.

10 Elfstrom J, Lindgren S. Disappearance of phenazone from plasma in patients with obstructive jaundice. Eur J Clin Pharmacol 1974; 7: 467-71. 